\title{
UJI TOKSISITAS EKSTRAK DAUN BINAHONG (Anredera cordifolia (Ten.) Steenis) TERHADAP LARVA UDANG Artemia salina Leach DENGAN METODE BRINE SHRIMP LETHALITY TEST (BSLT)
}

\author{
Nur Jazilah, A.Ghanaim Fasya, Rachmawati Ningsih, Ahmad Abtokhi
}

Jurusan Kimia, Fakultas Sains dan Teknologi, UIN Maulana Malik Ibrahim Malang

\begin{abstract}
Binahong leaf (Anredera cordifolia (Ten.) Steenis) is part of a drugs plants potency that can cure many kind of illnes include as drug anticancer. This risset have whit the goal for: (1) To know toxicity level of each extract binahong leaf (Anredera cordifolia (Ten) Steenis) in each solvent $n$-hexane, ethyl acetate and ethanol for level mortality larva shrimp Artemia salina Leach. (2) To Know a level of compounds that there are into extract binahong leaf (Anredera cordifolia (Ten) Steenis) with the best toxicity.

The rissed have done by extracting sample with solvent n-hexane by next wiht solvent ethyl acetate and ethanol. Concentrated extract that got in used to exam toxicity for shrimp larva BSLT and phytochemical test reagent. Mortality artemia salina by with probit analysis to know value of $\mathrm{LC}_{50}$.

The result from this risset show on each extract binahong leaf (Anredera cordifiola (Ten) Steenis) have level of toxicity on shrimp larva Artemia salina Leach, show with value $\mathrm{LC}_{50}<1000 \mathrm{ppm}$. The level of toxicity extract ethanol, extract ethyl acetate and n-hexane extract is an value $\mathrm{LC}_{50}$ a lot $7.35702 \mathrm{ppm}, 106.992 \mathrm{ppm}$ and $175.800 \mathrm{ppm}$. Into ethanol extract have done phytochemical test reagent there are leve alkaloids, flavonoids, tannins, triterpenoin/steroids and saponins. Lavel of that compounds show there are potency bioactivity on shrimp larva Artemia salina Leach.
\end{abstract}

Keyword: Anredera cordifiola (Ten) Steenis, Artemia salina Leach, Toxicity Test and BSLT.

\section{ABSTRAK}

Daun binahong (Anredera cordifolia (Ten.) Steenis) adalah bagian dari tanaman obat potensial yang dapat mengatasi berbagai jenis penyakit termasuk sebagai obat antikanker. Penelitian ini dilakukan dengan tujuan untuk: (1) Mengetahui tingkat toksisitas masing-masing ekstrak daun binahong (Anredera cordifolia (Ten) Steenis) dalam tiap pelarut n-heksana, etil asetat dan etanol terhadap tingkat mortalitas larva udang Artemia salina Leach. (2) Mengetahui golongan senyawa yang terdapat dalam ekstrak daun binahong (Anredera cordifolia (Ten) Steenis) dengan toksisitas yang terbaik.

Penelitian dilakukan dengan mengekstraksi sampel dengan pelarut n-heksana yang dilanjutkan dengan pelarut etil asetat dan etanol. Ekstrak pekat yang diperoleh digunakan untuk uji toksisitas terhadap larva udang BSLT dan uji fitokimia dengan reagen. Data kematian Artemia salina dianalisis dengan analisis probit untuk mengetahui nilai $\mathrm{LC}_{50}$.

Hasil dari penelitian menunjukkan pada masing-masing ekstrak daun binahong (Anredera cordifiola (Ten) Steenis) memiliki tingkat toksisitas terhadap larva udang Artemia salina Leach, ditunjukkan dengan nilai $\mathrm{LC}_{50}<$ 1000 ppm. Tingkat toksisitas ekstrak etanol, ekstrak etil asetat dan ekstrak n-heksana yaitu dengan nilai LC $_{50}$ sebesar 7,35702 ppm, 106,992 ppm dan 175,800 ppm. Pada ekstrak etanol dilakukan uji fitokimia denga reagen yaitu adanya golongan senyawa alkaloid, flavonoid, tanin, triterpenoid/steroid dan saponin. Golongan senyawasenyawa tersebut yang menunjukkan adanya potensi bioaktivitas terhadap larva udang Artemia salina Leach.

Kata Kunci: Binahong, Artemia salina Leach, Uji Toksisitas dan BSLT.

\section{PENDAHULUAN}

Tanaman binahong (Anredera cordifolia (Ten.) Steenis) adalah tanaman obat potensial yang dapat mengatasi berbagai jenis penyakit. Binahong tumbuh menjalar dan panjangnya dapat mencapai 5 meter, berbatang lunak berbentuk silindris dan pada ketiak daun terdapat seperti umbi yang bertekstur kasar. Daunnya tunggal dan mempunyai tangkai pendek, bersusun berselang-seling dan berbentuk jantung. Panjang daun antara 5-10 cm dan mempunyai lebar antara 3-7 cm. Seluruh bagian tanaman binahong dapat 
dimanfaatkan, mulai dari akar, batang, daun, umbi dan bunganya (Manoi , 2009).

Zat bioaktif yang ada pada tanaman binahong dapat membantu proses penyembuhan penyakit-penyakit degeneratif seperti kerusakan ginjal, diabetesdan lain-lainnya. Kandungan metabolit sekunder dalam binahong yang mempunyai aktivitas sebagai antioksidan dan antimikroba/antibiotik sangat baik dipakai sebagai bahan baku untuk obat tradisional (Manitto, 1992).

Tanaman binahong mengandung fenol, flavonoid, saponin, triterpenoid, steroid dan alkaloid (Astuti dkk., 2011), adanya aktivitas dari senyawa fitokimia yang berfungsi menghancurkan mikroba terutama pada kelompok bakteri gram positif (Rios dan Rico, 2005).

Penelitian ini bertujuan untuk mengetahui potensi ekstrak yang bersifat aktif dilakukan pengujian bioaktivitasnya dengan uji toksisitas terhadap larva udang Artemia salina (metode Brine Shrimp Lethality Test) dan mengetahui golongan senyawa yang terdapat dalam ekstrak daun binahong (Anredera cordifolia (Ten) Steenis) dengan toksisitas yang terbaik.

\section{METODE PENELITIAN}

2.1. Alat

Alat yang digunakan dalam penelitian ini adalah oven, blender, kaca arloji, cawan penguap, timbangan analitik, gelas ukur $100 \mathrm{~mL}$, erlenmeyer $300 \mathrm{~mL}$, pengaduk kaca, penyaring Buchner, rotary evaporator, beaker glass $100 \mathrm{~mL}$, desikator, pipet tetes, pipet ukur, tabung reaksi, penjepit, corong kaca, labu ukur, pipet mikro, bejana untuk penetasan telur udang, lampu dan botol vial

\subsection{Bahan}

Bahan utama yang digunakan dalam penelitian ini adalah daun binahong (Anredera cordifiola (Ten) Steenis), etanol, etil asetat dan n-heksana, asam sulfat, logam $\mathrm{Mg}$, Formaldehid, asam klorida, asam asetat anhidrida, reagen mayer, asam asetat glasial, reagen Dragendrof, regen Lieberman-Burchard, larutan gelatin, kertas 119 saring, aluminium foil, larva udang (Artemia salina Leach), dimetil sulfoksida (DMSO), ragi roto dan air laut.

\subsection{Uji kadar air}

Sampel dipotong kecil-kecil, ditimbang sebanyak $5 \mathrm{~g}$ dan dimasukkan ke dalam cawan yang telah diketahui beratnya, selanjutnya dikeringkan di dalam oven pada suhu $100-105^{\circ} \mathrm{C}$ selama sekitar 1 jam. Sampel kering didinginkan dalam desikator dan ditimbang. Sampel dipanaskan kembali dalam oven \pm 20 menit pada suhu yang sama, didinginkan dalam desikator dan ditimbang kembali. Perlakuan ini diulangi sampai tercapai berat konstan. Kadar air dihitung menggunakan rumus:

$$
\begin{gathered}
\text { kadar air }=\frac{(\text { berat awal }- \text { berat akhir })}{(\text { berat awal })} \\
\times 100 \%
\end{gathered}
$$

\subsection{Preparasi sampel}

$1 \mathrm{Kg}$ daun binahong dicuci bersih, diiris kecil-kecil dan dikeringkan dalam oven dengan suhu $37-40{ }^{\circ} \mathrm{C}$ selama $1-2$ jam kemudian dijemur sampai diperoleh berat konstan (kering). Daun binahong yang kering kemudian dihaluskan menjadi serbuk dan diayak dengan ukuran 60 mesh.

\subsection{Ekstraksi senyawa aktif dengan maserasi}

Ekstraksi komponen aktif dilakukan dengan cara ekstraksi maserasi/perendaman dengan pelarut yang memiliki tingkat kepolaran yang berbeda yaitu n-heksana, etil asetat dan metanol. Serbuk daun binahong ditimbang sebanyak $50 \mathrm{~g}$ direndam dengan n-heksana sebanyak 150 $\mathrm{mL}$ dan dimaserasi selama 24 jam dengan pengocokan selama 3 jam menggunakan Shaker, kemudian disaring dan ampas yang diperoleh dimaserasi kembali dengan pelarut dan perlakuan yang sama sampai tiga kali penggulangan sehingga diperoleh fitrat yang warnanya pucat. Selanjutnya disaring dan ampas dikeringkan agar terbebas dari pelarut n-heksana. Ketiga filtrat yang diperoleh selanjutnya digabung menjadi satu.

Ampas dipartisi dengan pelarut etil asetat dan etanol dengan mengunakan cara 
seperti diatas, ketiga ekstrak yang diperoleh dipekatkan dengan rotary evaporator sampai diperoleh ekstrak pekat n-heksana, etil asetat dan etanol.

\subsection{Toksisitas dengan larva udang Artemia salina Leach}

\subsubsection{Penetasan telur}

Disiapkan bejana untuk penetasan telur udang. Di satu ruang dalam bejana tersebut diletakkan lampu untuk menghangatkan suhu dalam penetasan, sedangkan di ruang sebelahnya diberi air laut. Kedalam air laut dimasukkan \pm 50-100 mg telur udang untuk ditetaskan. Pada bagian telur ditutup dengan aluminium foil, dan lampu dinyalakan selama 24-48 jam untuk meneteskan telur.

\subsubsection{Uji Toksisitas}

Perlakuan uji toksisitas dilakukan sebanyak 3 kali ulangan pada masingmasing ekstrak sampel. Botol disiapkan untuk pengujian, masing-masing ekstrak membutuhkan 8 botol dan 3 botol sebagai kontrol. Ekstrak kental n-heksana, etil asetat, dan etanol ditimbang sebanyak 100 mg dan dilarutkan dengan menggunakan pelarutnya masing-masing sebanyak $10 \mathrm{~mL}$ untuk membuat larutan stok $10.000 \mathrm{ppm}$. Dari larutan stok tersebut kemudian dipipet sesuai dengan konsentrasinya, sehingga konsentrasinya masing-masing larutan menjadi $5,10,15,20,25,50,75$ dan 100 ppm. dimasukkan ke dalam botol dan pelarutnya dibiarkan selama 24 jam.

Selanjutnya dimasukkan $100 \mu \mathrm{L}$ dimetil sulfoksida (DMSO), $2 \mathrm{~mL}$ air laut dan 10 ekor larva udang. Kemudian ditambahkan air laut sampai volumenya menjadi $10 \mathrm{~mL}$. Kontrol dibuat dengan dimasukkan $2 \mathrm{~mL}$ air laut, $100 \mu \mathrm{L}$ dimetil sulfoksida, 10 ekor larva udang dan setetes larutan ragi roti ke dalam botol, kemudian ditambahkan air laut sampai volumenya menjadi $10 \mathrm{~mL}$. Pengamatan dilakukan selama 24 jam terhadap kematian larva udang.

Selanjutnya dihitung mortalitas dengan cara: akumulasi mati dibagi jumlah akumulasi hidup dan mati (total) dikali 100
$\%$. Grafik dibuat dengan log konsentrasi sebagai sumbu $\mathrm{x}$ terhadap mortalitas sebagai sumbu y. Nilai LC $_{50}$ merupakan konsentrasi dimana zat menyebabkan kematian $50 \%$ yang diperoleh dengan memakai persamaan regresi linier $\mathrm{y}=\mathrm{a}+$ bx. Suatu zat dikatakan aktif atau toksik bila nilai $\mathrm{LC}_{50}<1000$ ppm untuk ektrak dan < 30 ppm untuk suatu senyawa (Juniarti dkk., 2009).

\subsection{Uji Fitokimia Dengan Reagen \\ 2.7.1. Uji Alkaloid}

Ekstrak daun binahong dimasukkan dalam tabung reaksi, ditambah $0,5 \mathrm{~mL} \mathrm{HCl}$ $2 \%$ dan larutan dibagi dalam dua tabung. Tabung I ditambahkan 2-3 tetes reagen Dragendorff, tabung II ditambahkan 2-3 tetes reagen Mayer. Jika tabung I terbentuk endapan jingga dan pada tabung II terbentuk endapan kekuning-kuningan, menunjukkan adanya alkaloid.

\subsubsection{Uji Flavonoid}

Ekstrak daun binahong dimasukkan dalam tabung reaksi kemudian dilarutkan dalam 1-2 mL metanol panas $50 \%$. Setelah itu ditambah logam $\mathrm{Mg}$ dan 4-5 tetes $\mathrm{HCl}$ pekat. Larutan berwarna merah atau jingga yang terbentuk, menunjukkan adanya flavonoid.

\subsubsection{Uji Tanin}

\subsubsection{Uji dengan $\mathrm{FeCl}_{3}$}

Ekstrak daun binahong ditambahkan dengan 2-3 tetes larutan $\mathrm{FeCl}_{3} 1 \%$. Jika larutan menghasilkan warna hijau kehitaman atau biru tinta, maka bahan tersebut mengandung tanin.

\subsubsection{Uji dengan Larutan Gelatin}

Ekstrak daun binahong dimasukkan dalam tabung reaksi ditambah dengan larutan gelatin. Jika terbentuk endapan putih, menunjukkan adanya tanin.

\subsubsection{Uji Saponin}

Ekstrak daun binahong dimasukkan dalam tabung reaksi ditambah $10 \mathrm{~mL}$ air sambil dikocok selama 1 menit, apabila menimbulkan busa ditambahkan 2 tetes $\mathrm{HCl} 1 \mathrm{~N}$, bila busa yang terbentuk bisa 
tetap stabil maka ekstrak positif mengandung saponin.

\subsubsection{Uji Triterpenoid dan Steroid}

Ekstrak daun binahong dimasukkan dalam tabung reaksi, dilarutkan dalam 0,5 $\mathrm{mL}$ kloroform lalu dipanaskan dan didinginkan. Diambil $1 \mathrm{~mL}$ dan dimasukkan dalam tabung reaksi lalu diteteskan pereaksi Lieberman-burchard. Jika hasil yang diperoleh berupa cincin kecoklatan atau violet pada perbatasan dua pelarut menunjukkan adanya triterpenoid, sedangkan jika terbentuk warna hijau kebiruan menunjukkan adanya steroid.

\subsection{Analisis Data}

Data yang diperoleh dibuat dalam bentuk tabel dan grafik, kemudian dideskripsikan hasilnya. Tingkat toksisitas larva udang Artemia salina Leach dapatdiketahui dengan melakukan uji $\mathrm{LC}_{50}$ menggunakan program MINITAB 14.

\section{HASIL DAN PEMBAHASAN \\ 3.1. Analisis Kadar Air}

Penentuan kadar air ini sangat penting karena jumlah kadar air yang terkandung dalam suatu sampel akan berpengaruh pada stabilitas dan kualitas sampel. Kandungan air dalam sampel akan mempengaruhi proses ekstraksi senyawa aktif. Semakin rendah kadar air dalam suatu sampel, maka pelarut akan semakin mudah untuk mengekstrak senyawa aktif dalam sampel sehingga kandungan senyawa yang dihasilkan semakin banyak. Pengukuran kadar air ini dilakukan pengulangan sebanyak 3 kali untuk memperoleh keakuratan data dan didapatkan rata-rata $79,9311 \%$ pada sampel daun binahong segar.

\subsection{Preparasi Sampel}

Daun binahong kering berwarna hijau kecoklatan dihaluskan menjadi serbuk menggunakan blender, sehingga diperoleh serbuk sampel berwarna hijau dan memiliki bau seperti daun pacar, fungsi sampel dihaluskan menjadi serbuk agar dalam proses pemisahan dihasilkan ekstrak yang maksimal, disamping itu mempermudah 121 proses ekstraksi. Pengayakan serbuk menggunkan ayakan dengan ukuran 60 mesh, dikarenakan apabila semakin kecil bentuk sampel maka semakin besar luas permukaan yang diperoleh, sehingga dalam proses ekstraksi semakin efektif.

Serbuk dengan penghalusan yang tinggi kemungkinan sel-sel yang rusak juga semakin besar, sehingga memudahkan pengambilan bahan kandungan lansung oleh bahan pelarut (Octavia, 2009).

\subsection{Ekstraksi maserasi}

Tabel 1. Hasil maserasi serbuk daun binahong (Anredera cordifolia (Ten) Steenis)

\begin{tabular}{|c|c|c|c|c|}
\hline Pelarut & $\begin{array}{l}\text { Volume } \\
\text { pada } \\
\text { filtrat } \\
(\mathrm{mL})\end{array}$ & $\begin{array}{l}\text { Perubahan } \\
\text { warna } \\
\text { filtrat }\end{array}$ & $\begin{array}{l}\text { Warna } \\
\text { ekstrak } \\
\text { pekat }\end{array}$ & $\begin{array}{l}\text { Berat } \\
\text { ekstrak } \\
\text { pekat }(g)\end{array}$ \\
\hline $\begin{array}{l}\text { n- } \\
\text { heksana }\end{array}$ & 86 & $\begin{array}{l}\text { Hijau tua } \\
\text { pekat } \\
\text { menjadi } \\
\text { hijau pucat }\end{array}$ & $\begin{array}{l}\text { Kuning } \\
\text { kehijauan }\end{array}$ & 1,2183 \\
\hline $\begin{array}{l}\text { Etil } \\
\text { asetat }\end{array}$ & 125 & $\begin{array}{l}\text { Hijau } \\
\text { kecoklatan } \\
\text { menjadi } \\
\text { hijau } \\
\text { kecoklatan } \\
\text { pucat }\end{array}$ & $\begin{array}{l}\text { Hijau tua } \\
\text { kecoklatan }\end{array}$ & 0,9178 \\
\hline Etanol & 168 & $\begin{array}{l}\text { Hijau } \\
\text { kecoklatan } \\
\text { menjadi } \\
\text { hijau } \\
\text { kekuningan } \\
\text { pucat }\end{array}$ & Hijau tua & 1,1296 \\
\hline
\end{tabular}

Berdasarkan Tabel 1 dapat diketahui bahwa berat ekstrak pekat n-heksana dan ekstrak pekat etanol menunjukkan nilai yang hampir sama besarnya, hal ini menunjukkan bahwa kandungan senyawasenyawa non polar dan polar dalam daun binahong lebih besar daripada senyawasenyawa semipolar. Hasil ekstrak pekat yang diperoleh pada masing-masing pelarut digunakan untuk uji selanjutnya, yaitu uji toksisitas dengan menggunkan Artemia salina Leach dan uji fitokimia dengan menggunakan reagen.

\subsection{Uji Toksisitas Menggunakan Larva Udang Artemia salina Leach}

\subsubsection{Penetasan Telur}

Preoses penetasan Artemia salina Leach ada beberapa tahap yaitu tahap hidrasi, pecahnya cangkang dan tahap 
payung atau tahap pengeluaran. Tahap hidrasi terjadi penyerapan air sehingga telur yang diawetkan dalam bentuk kering tersebut akan menjadi bulat dan aktif bermetabolisme. Tahap selanjut yaitu tahap pecahnya cangkang yang disusul dengan tahap pecahnya payung yang terjadi beberapa saat sebelum naupil (larva) keluar dari cangkang.

Artemia yang baru menetas disebut dengan nauplius. Nauplius berwarna orange, berbentuk bulat lonjong dengan panjang sekitar 400 mikron, lebar sekitar 170 mikron, dan berat $0,002 \mathrm{mg}$. Ukuranukuran tersebut sangat tergantung berdasarkan strainnya.

\subsubsection{Uji Toksisitas}

Perlakuan uji toksisitas dilakukan 3 kali pengulangan pada masing-masing ekstrak sampel. Larutan uji dibuat dari larutan stok 10000 ppm dengan mengambil $5 \mu \mathrm{L}, 10 \mu \mathrm{L}, 15 \mu \mathrm{L}, 20 \mu \mathrm{L}, 25 \mu \mathrm{L}, 50 \mu \mathrm{L}$, $75 \mu \mathrm{L}$ dan $100 \mu \mathrm{L}$ masing ekstrak ke dalam botol vial. Selanjutan pelarut masingmasing ekstrak diuapkan sampai kering dalam desikator agar kematian larva tidak dipegaruhi pelarutnya. Setelah pelarutnya mengering, ditimbahkan dengan $100 \mu \mathrm{L}$ DMSO (dimetil sukfoksida) dan sedikit air laut kemudian dilarutkan sampai ekstraknya larut seluruhnya. Pelarutan ekstrak dengan air laut sering menimbulkan masalah karena adanya perbedaan tingkat kepolaran, ekstrak tidak mampu larut dengan air laut sehingga digunakan DMSO untuk melarutkannya. DMSO digunakan sebagai sulfaktan karena ekstrak tidak dapat larut dalam air laut. Surfaktan merupakan senyawa yang memiliki ujung hidrofilik dan hidrofibik sehingga dapat melarutkan ekstrak dengan air laut.

Ekstrak yang telah larut denga air laut selanjutnya dipindahkan dalam labu ukur $10 \mathrm{~mL}$. Larva udang Artemia salina Leach selanjutnya dimasukkan sebanyak 10 ekor ke dalam labu ukur yang berisi ekstrak yang telah larut dengan air laut. Kemudian ditambahkan 1 tetes larutan ragi roti dan ditambahkan denga air laut sampai tanda batas. Ragi roti merupakan makanan untuk artemia, dibuat dalam bentuk larutan karena artemia hanya dapat menelan makanan yang berukuran kecil yaitu kekurang dari 50 mikron dan artemia akan menelan makanannya secara langsung.

Kontrol dibuat dengan cara yang sama yaitu denga membuat larutan yang sama kecuali penambahan ekstrak. Hasil uji toksisitas ketiga ekstrakdan hasil analisa dengan program Minitab 14 dengan tingkat kepercayaan $95 \%$ serta Tabel data kematian larva dapat dilihat pada Lampiran 6. Kurva mortalitas larva udang dapat dilihat pada Gambar 1, 2 dan 3.

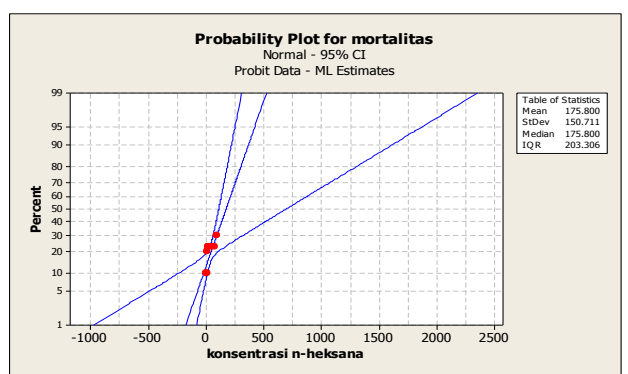

Gambar 1. Kurva mortalitas larva udang Artemia salina Leach ekstrak n-heksana

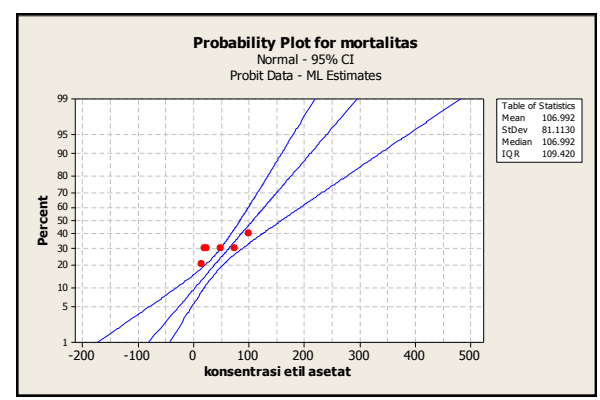

Gambar 2. Kurva mortalitas larva udang Artemia salina Leach ekstrak etil asetat

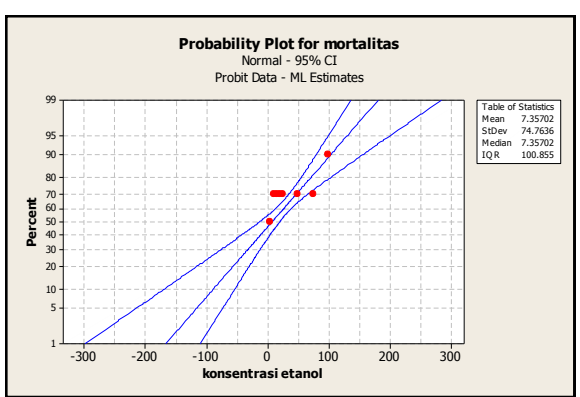

Gambar 3. Kurva mortalitas larva udang Artemia salina Leach ekstrak etanol

Gambar 1, 2 dan 3 tersebut menunjukkan bahwa semakin besar nilai konsentrasi masing-masing ekstrak maka 
mortalitas terhadap Artemia juga semakin besar. Daerah di sebelah kanan kurva menunujukkan presentasi kematian Artemia sedangkan daerah di sebelah kiri kurva menunjukkan presentasi Artemia yang masih bertahan hidup pada masing-masing konsentrasi ekstrak pelarut.

Adanya penambahan masingmasing ekstrak meyebabkan kematian Artemia yang mengalami disorientasi gerak (geraknya tidak beraturan). Hal ini membuktikan adanya sifat toksik dari masing-masing ekatrak daun binahong dengan adanya kematian pada hewan uji Artemia. Dan berdasarkan kurva di atas, ketiga ekstrak n-heksana, etil asetat dan etanol, masing-masing diperoleh nilai $\mathrm{LC}_{50}$ sebesar 175,800 ppm, 106,992 ppm dan 7,35702 ppm yang dapat dilihat dari median pada masing-masing kurva di atas. Hasil LC $_{50}$ ketiga ekstrak tersebut menunjukkan bahwa tingkat toksisitas senyawa dalam ekstrak etanol lebih besar daripada ekstrak n-heksana dan ekstrak etil asetat dan dapat dilihat pada Tabel 2 .

Tabel 2. Hasil Nilai LC $_{50}$ pada Masingmasing Ekstrak

\begin{tabular}{|l|l|}
\hline Sampel ekstrak & Nilai $\mathrm{LC}_{50}(\mathrm{ppm})$ \\
\hline n-heksana & 175,800 \\
\hline etil asetat & 106,992 \\
\hline Etanol & 7,35702 \\
\hline
\end{tabular}

Meyer (1982) dalam Farihan (2006) melaporkan bahwa suatu ekstrak menunjukkan aktivitas ketoksikan dalam BSLT jika ekstrak dapat menyebabkan kematian $50 \%$ hewan uji pada konsentrasi kurang dari 1000 ppm. Pernyataan di atas menunjukkan ketiga ekstrak daun binahong bersifat toksik terhadap Artemia karena memiliki nilai $\mathrm{LC}_{50}<1000 \mathrm{ppm}$.

Hasil LC $_{50}$ ketiga ekstrak tersebut menunjukkan bahwa tingkat toksisitas senyawa dalam ekstrak etanol > ekstrak etil asetat > ekstrak n-heksana. Ketoksikan ekstrak etanol lebih toksik daripada ekstrak n-heksana dan etil asetat dikarenakan kandungan senyawa yang terdapat pada ekstrak etanol merupakan senyawasenyawa yang mempunyai peran penting sebagai antimikroba/antibiotik.

\subsection{Uji Fitokimia}

Tabel 3. Hasil pengamatan uji fitokimia terhadap Ekstrak etanol

\begin{tabular}{|l|l|}
\hline Golongan Senyawa & Ekstrak Etanol \\
\hline Alkaloid & ++ \\
\hline Flavonoid & ++ \\
\hline Tanin & + \\
\hline Triterpenoid/Steroid & + \\
\hline Saponin & ++ \\
\hline
\end{tabular}

Keterangan: tanda ++: terkandung senyawa lebih banyak/ warna pekat tanda + : terkandung senyawa/warna muda

Hasil identifikasi senyawa aktif berdasarkan uji fitokimia dengan menggunakan reagen menunjukkan ketoksikan disebabkan adanya senyawa aktif golongan alkaloid, flavonoid, tanin, triterpenoid/steroid dan saponin. Pada daun binahong kandungan metabolit sekunder yang tinggi adalah flavonoid, alkoloid dan saponin. Kandungan senyawa ini mempunyai aktifitas sebagai antioksidan dan antimikroba/antibiotik, sehingga sangat baik dipakai bahan baku untuk obat tradisional.

\section{KESIMPULAN DAN SARAN Kesimpulan}

Masing-masing ekstrak daun binahong (Anredera cordifiola (Ten) Steenis) memiliki tingkat toksisitas terhadap larva udang Artemia salina Leach, ditunjukkan dengan nilai $\mathrm{LC}_{50}<1000$ ppm. Tingkat toksisitas ekstrak etanol > ekstrak etil asetat > ekstrak n-heksana yaitu dengan nilai LC $_{50}$ sebesar 7,35702 ppm, 106,992 ppm dan 175,800 ppm.

Uji fitokimia pada ekstrak etanol golongan senyawa yang menunjukkan keberadaan golongan senyawa alkaloid, flavonoid, tanin, triterpenoid/steroid dan saponin. 
Saran

Hasil uji pendahuluan dengan metode BSLT menunjukkan dalam ketiga variasi ekstrak pelarut daun binahong memiliki potensi bioaktivitas, sehingga perlu dilakukan pengujian bioaktivitas lebih lanjut terhadap tanaman ini. Jika akan dilakukan penelitian selanjutnya untuk mengetahui masing-masing senyawanya perlu dilakukan uji KLTP dengan penacarian eluen yang terbaik.

\section{DAFTAR PUSTAKA}

Astuti SM, Mimi SAM, Retno ABM. dan Awalludin R. 2011.a. Determination of Saponin Compound from Anredera cordifolia (Ten) Steenis (Binahong) to potential treatment for several deseases. Journal of Agricultural Science, Canadian Center of Science and Education. Vol 3.No 4, December, 2011 pp 224 -232 .

Farihah. 2006. Uji Toksisitas Ekstrak Daun Ficus benjamina L terhadap Artemia salina Leach dan Profil Kromatografi Lapis Tipis. Skripsi Diterbitkan. Surakarta: Fakultas Farmasi Universitas Muhammadiyah Surakarta.

Juniarti, Delvi O., dan Yuhernita. 2009. Kandungan Senyawa Kimia, Uji Toksisitas (Brine Shrimp Lethality Test) Dan Antioksidan (1,1diphenyl-2-pikrilhydrazyl) Dari Ekstrak Daun Saga (Abrus precatorius L.). Jurnal Kimia. Jakarta: Fakultas Kedokteran. Universitas YARSY.

Manitto P. 1992. Biosintesis Produk Alami. Penerjemah Koen Sumardiyah. Semarang: IKIP Press. Hal. 70-79.

Manoi, F. 2009. Binahong (Anredera cordifolia)(Ten) Steenis Sebagai Obat. Jurnal Warta Penelitian Dan Pengembangan Tanaman Industri. Volume 15 Nomor 1:3.

Meyer, B.N., Ferrigni, N.R., Putnam, J.E., Jacobsen, L.B., Nichols, D.E., dan McLaughin, J.L., 1982, Brine
Shrimp: A Convenient General

Bioassay for Active Plant

Constituent, Planta Medica. 45:3134.

Rios JL. dan Rico MC. 2005. Medicinal Plants and Antimicrobial Activity. Respective paper. 